\title{
Opinions and Perceptions of Gynecologists and Midwives on the Use of the Intrauterine Device in Senegal
}

\author{
Hadja Maimouna Barro Daff ${ }^{*}$, Khalifa Babacar Mansour Fall1, Youssoupha Touré1, \\ Aïssatou Mbodji1,2, Moussa Diallo1,3, Abdoul Aziz Diouf ${ }^{1,3}$, Magatte Mbaye1,2, \\ Khalifa Babacar Gueye ${ }^{1}$, Babacar Biaye ${ }^{1}$, Alassane Diouf ${ }^{1,3}$ \\ ${ }^{1}$ Public Institution Aristide-Le Dantec Health Center, Gynecological and Obstetric Clinic, Cheikh Anta Diop University of Dakar, \\ Dakar, Senegal \\ ${ }^{2}$ Department of Obstetrics and Gynecology, Phillipe Maguilene Senghor Center, Yoff, Senegal \\ ${ }^{3}$ Department of Obstetrics and Gynecology, Pikine University Hospital, Thiaroye Pikine, Senegal \\ Email: ^hmbdaff@gmail.com
}

How to cite this paper: Daff, H.M.B., Fall, K.B.M., Touré, Y., Mbodji, A., Diallo, M., Diouf, A.A., Mbaye, M., Gueye, K.B., Biaye, B. and Diouf, A. (2021) Opinions and Perceptions of Gynecologists and Midwives on the Use of the Intrauterine Device in Senegal. Open Journal of Obstetrics and $G y$ necology, 11, 1484-1493.

https://doi.org/10.4236/ojog.2021.1111139

Received: September 30, 2021

Accepted: November 9, 2021

Published: November 12, 2021

Copyright $\odot 2021$ by author(s) and Scientific Research Publishing Inc. This work is licensed under the Creative Commons Attribution International License (CC BY 4.0).

http://creativecommons.org/licenses/by/4.0/ (c) (i) Open Access

\begin{abstract}
Objective: The purpose of this study was to analyze the opinions of gynecologists, midwives, and interns/Specialist students practicing in Senegal about the use of IUD, and to assess factors that stand as obstacles to IUD prescribing. Patients and methods: An online questionnaire was developed to assess providers' IUD practices and attitudes. The questionnaire was based on the one used in a Swiss study on the same topic. The platform used was Google forms. The questionnaire was shared in associative platforms involving gynecologists, midwives and interns/Specialist students. Results and comments: We received 292 feedbacks. Gynecologists represented $13.7 \%$ of the sample, interns and specialist students $11.3 \%$ and midwives $76 \%$. Parity is a determining factor in IUD selection. The care-providers were concerned about the followings, which might have prevented the use of IUD, even though it was indicated: infections (75.7\%), pelvic pain (61.3\%), expulsion (48.3\%), increased risk of perforation (46.9\%), women's appreciation (45.2\%), ectopic pregnancy (33.9\%) and sexual behavior (28.4\%). Conclusion: Our study reveals that providers' apprehensions and concerns severely limit the availability of IUDs. These concerns are often unfounded, based on personal experiences and not on official recommendations. Parity is a major obstacle.
\end{abstract}

\section{Keywords}

Intrauterine Device, IUD, Parity, Gynecologists, Midwives, Interns 


\section{Introduction}

The intrauterine device (IUD) is the world's oldest contraceptive method, used by more than 168 million women worldwide [1]. However, prevalence remains unevenly distributed. Its effectiveness has been proven with a Pearl Index of around $0.1 \%$. It is a long-lasting, safe, reversible method that does not interfere with breastfeeding. It is also relatively inexpensive, practical and has a very low complication rate [2] [3]. However, despite its advantages, IUD use is declining significantly, particularly in Senegal. Indeed, IUD use reached a record high in 1992 and 1993, representing 27\% of all methods used in Senegal. In 1999, the rate was only $11 \%$ [4], and today it is estimated at $1.6 \%$ [5].

This low IUD prevalence is often due to misconceptions about the IUD. Many people believe that the IUD is associated with high rates of migration, infertility, and induced abortion. However, some barriers may be due to the practice of certain practitioners, gynecologists and/or midwives.

Indeed, physicians' knowledge and attitudes about contraceptive methods are important, but generally overlooked, factors in the use and continuation of these methods. For the IUD, there is a clear association between providers' knowledge and the likelihood of recommending its insertion [6].

We therefore decided to conduct this study to collect and analyze the opinions of gynecologists and midwives practicing in Senegal about the use of IUD and to assess factors that act as obstacles to its prescription.

\section{Tools and Methods}

A 19-item questionnaire was developed to assess providers' practices and attitudes toward the IUD. The questionnaire was based on the one used in a Swiss study on the same topic. The platform used was Google forms. The questionnaire was shared in associative platforms involving gynecologists, midwives and interns/Specialist students.

The first 5 questions were designed to define socio-demographic characteristics such as age, gender, occupation, work environment and experience as a function of the number of years worked. Knowledge and use of the IUD was assessed on 8 questions. Frequency of contraceptive visits was assessed as $<10,10-$ 20 , and $>20$. Their ability to insert and teach the IUD was also assessed. The number of IUDs inserted by the practitioner, as well as the number of patients referred for insertion, were assessed in the following proportions: $<5,5-10,10-$ 20 and $>20$. A few questions were developed to assess practitioner attitudes based on parity (nulliparous-primary-multiparous). Regarding the advantages of the IUD, providers were asked to choose from a list of 12 advantages, including efficacy, high continuation rate, cost-effectiveness, reduced bleeding, women's appreciation, emergency contraception, reduced cancer risk, long-term contraception, rapid return to fertility, minimal contraindications and few drug interactions. The disadvantages of the IUD were also formulated as multiple choices among 12 criteria including lack of efficacy, pelvic pain, infections, infertility, difficulty of insertion, pain during insertion, ectopic pregnancy, not appreciated 
by women, age of the woman, religious beliefs, cycle disorders, sexual behavior, and risk of uterine perforation.

An open-ended question was developed to solicit opinions on how to increase the IUD use.

Data analysis was done using IBM SPSS Statistics 24. We used the Chi 2 Test and/or the Fisher test for univariate analysis of categorical variables. A multivariate analysis was undertaken using binary regression logistics to identify key barriers by profession and tears of experience.

\section{Results}

We received 292 responses. Gynecologists represented 13.7\% of the sample, interns and Specialist students $11.3 \%$ and midwives $76 \%$. Demographics, including age, occupation, gender, years of experience and practice location are presented in Table 1.

A small proportion of participants had never inserted (9.2\%) or prescribed an IUD (7.2\%). Eight-point two percent of participants had never been taught about IUD insertion. The common factor shared by these participants was the years of experience (Table 2).

Table 1. Socio-demographic profile of participants.

\begin{tabular}{|c|c|c|c|}
\hline & Number $(\mathrm{N})$ & Percentage (\%) & p-value \\
\hline \multicolumn{4}{|l|}{ Age } \\
\hline$\bullet<30$ & 40 & 13.7 & \\
\hline - $30-40$ & 216 & 74 & \\
\hline - $40-50$ & 26 & 8.6 & \\
\hline$\bullet>50$ & 11 & 3.8 & \\
\hline \multicolumn{4}{|l|}{ Sex } \\
\hline - Female & 261 & 89.4 & \\
\hline - Male & 31 & 10.6 & \\
\hline \multicolumn{4}{|l|}{ Profession } \\
\hline - Gynecologist & 37 & 12.7 & \\
\hline - Interns/DES & 33 & 11.3 & \\
\hline - Midwife & 222 & 76 & \\
\hline \multicolumn{4}{|l|}{ Place of practice } \\
\hline - Private & 14 & 4.8 & \\
\hline - Public & 256 & 7.5 & \\
\hline - Private and public & 22 & 87.7 & \\
\hline \multicolumn{4}{|l|}{ Years of experience } \\
\hline$\bullet<5$ & 81 & 27.7 & \\
\hline - $5-10$ & 140 & 47.9 & \\
\hline$\bullet>10$ & 71 & 24.3 & \\
\hline \multicolumn{4}{|c|}{ Monthly contraceptive consultation } \\
\hline$\bullet<10$ & 84 & 28.8 & \\
\hline - $10-20$ & 61 & 20.9 & \\
\hline - $>20$ & 147 & 50.3 & \\
\hline
\end{tabular}




\section{Continued}

\begin{tabular}{lcc}
\hline Number of IUDs insertions per month & \\
$\bullet<5$ & 219 & 75 \\
$\bullet 5-10$ & 63 & 21.6 \\
$\bullet 10-20$ & 3 & 1 \\
$\bullet>20$ & 7 & 2.4 \\
\hline Number of references for IUD insertion & & \\
$\bullet<5$ & 255 & 87.3 \\
$\bullet 5-10$ & 30 & 10.3 \\
$\bullet 10-20$ & 3 & 1 \\
$\bullet>20$ & 4 & 1.4 \\
\hline
\end{tabular}

Table 2. Knowledge of the IUD depending on the years of experience.

\begin{tabular}{|c|c|c|c|c|c|c|c|}
\hline & & $\begin{array}{l}\text { Years of experience } \\
5-10 \text { years }(n=140)\end{array}$ & $\begin{array}{l}\text { Years of experience } \\
<5 \text { years }(n=81)\end{array}$ & $\begin{array}{l}\text { Years of experience } \\
>10 \text { years }(\mathrm{n}=71)\end{array}$ & $\mathrm{n}$ & $\mathrm{p}$ & test \\
\hline \multirow{2}{*}{$\begin{array}{c}\text { Have you ever } \\
\text { inserted an IUD, } \mathrm{n}\end{array}$} & Yes & $128(91 \%)$ & $66(81 \%)$ & $71(100 \%)$ & 265 & $<0.001$ & Chi2 \\
\hline & No & $12(8.6 \%)$ & $15(19 \%)$ & $0(0 \%)$ & 27 & - & - \\
\hline \multirow{2}{*}{$\begin{array}{c}\text { Have you ever } \\
\text { prescribed an IUD, n }\end{array}$} & Yes & $131(94 \%)$ & $70(86 \%)$ & 70 (99\%) & 271 & 0.013 & Chi2 \\
\hline & No & $9(6.4 \%)$ & $11(14 \%)$ & $1(1.4 \%)$ & 21 & - & - \\
\hline \multirow{2}{*}{$\begin{array}{l}\text { Have you been taught } \\
\text { how to insert an IUD, } \mathrm{n}\end{array}$} & Yes & 127 (91\%) & $75(93 \%)$ & $66(93 \%)$ & 268 & 0.81 & Chi2 \\
\hline & No & $13(9.3 \%)$ & $6(7.4 \%)$ & $5(7 \%)$ & 24 & - & - \\
\hline
\end{tabular}

\subsection{Advantages of the IUD}

The main advantages listed by clinicians regarding IUD insertion were: long-term contraception (96.2\%), efficacy (89.8\%), rapid return to fertility (88.7\%), minimal contraindications (69.9\%), and few drug interactions (68.2\%). The benefits of IUD insertion according to study participants are reported in Figure 1.

\subsection{Obstacles to IUD}

The most frequently reported obstacles to IUD prescribing were dominated by infections (75.7\%), pelvic pain (61.3\%), expulsion (48.3\%), increased risk of perforation (46.9\%), women's appreciation (45.2\%), ectopic pregnancy (EP) (33.9\%) and sexual behavior (28.4\%). Figure 2 illustrates the main obstacles to IUD prescribing.

The six most frequently selected obstacles, and how these responses vary by occupation and years of experience, are presented in Figure 3 and Figure 4.

We performed a multivariate analysis taking into account profession and years of experience, concerns were shared by gynecologists, midwives and interns/Specialist students without statistically significant difference. However, they were more concerned about infections $(\mathrm{p}=0.87)$ and pelvic pain $(\mathrm{p}=0.11)$.

With regard to years of experience, a significant difference was found in those under 5 years of age who were less concerned about pelvic pain $(p=0.01)$. 


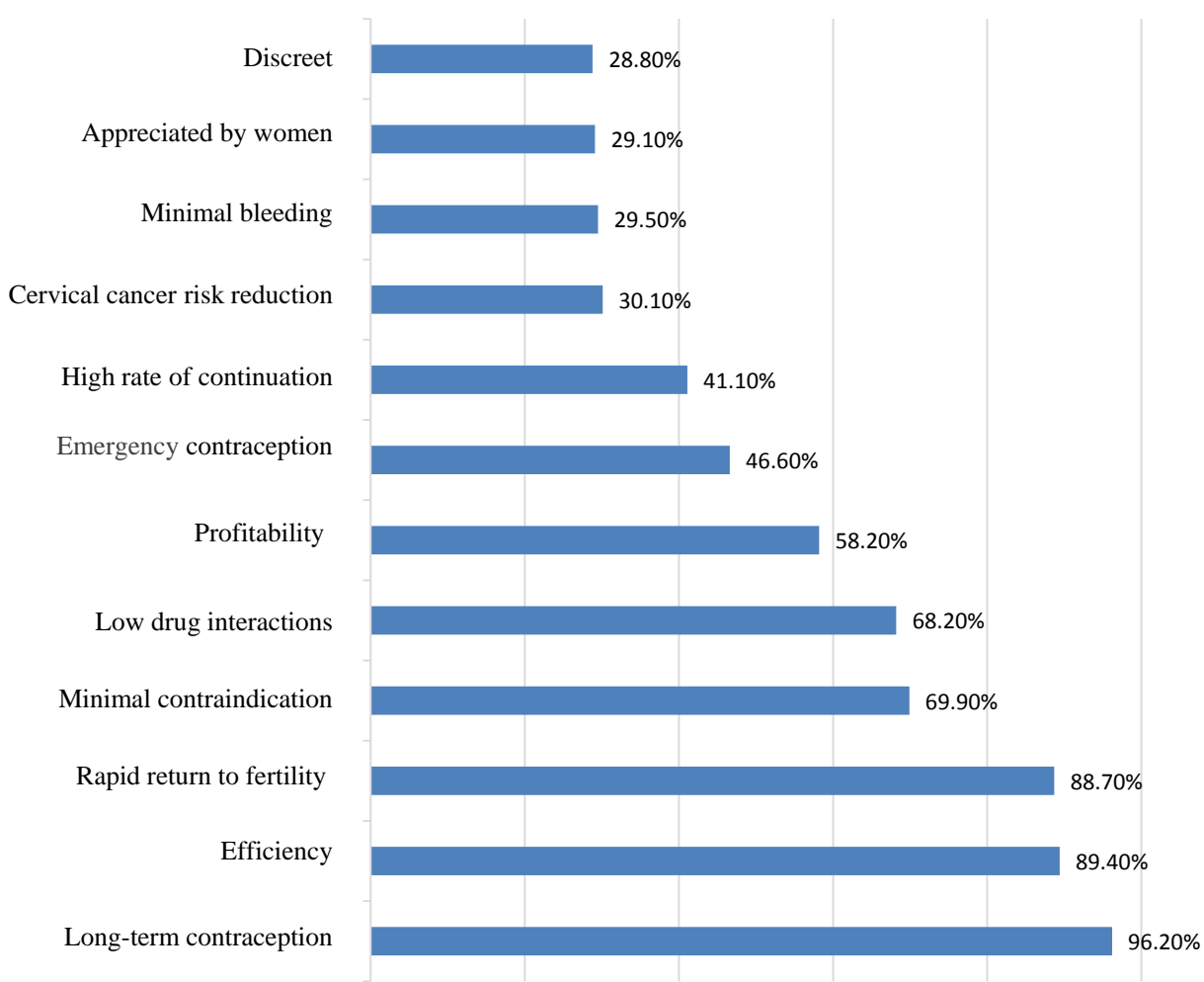

Figure 1. Advantages of IUD use according to study participants.

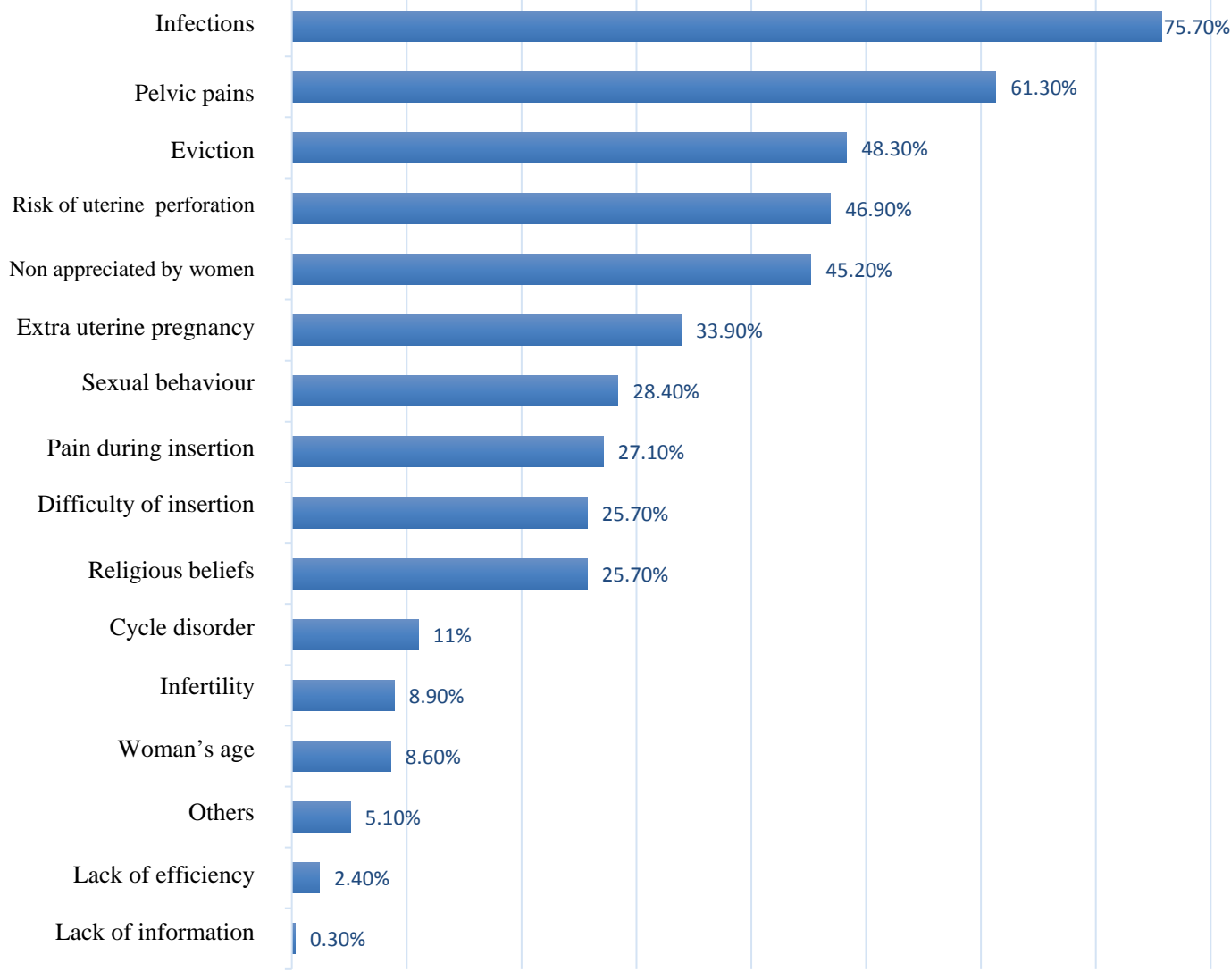

Figure 2. Obstacles to IUD according to the study participants. 


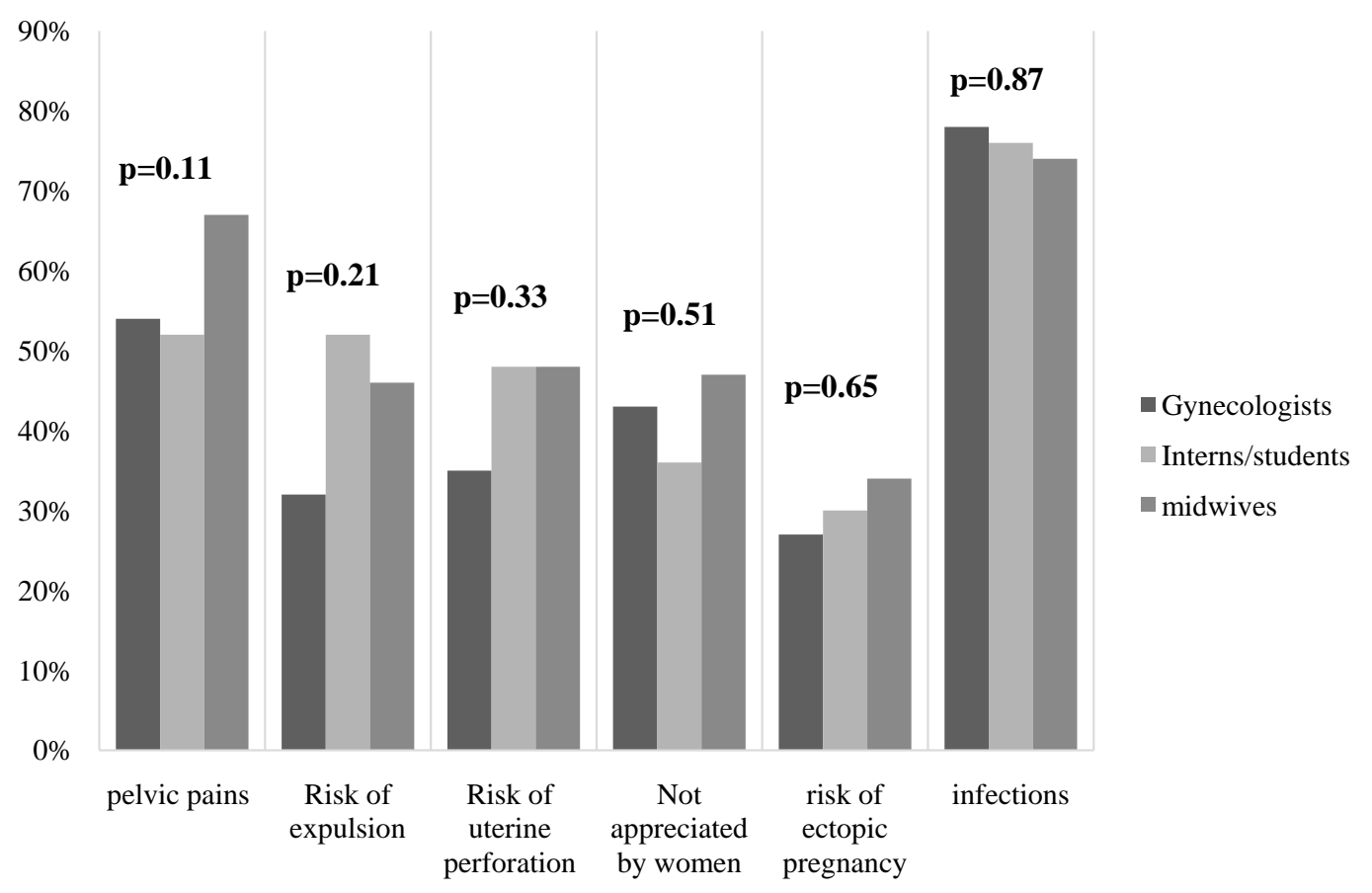

Figure 3. Perceived Obstacles to IUD Use by one's profession.

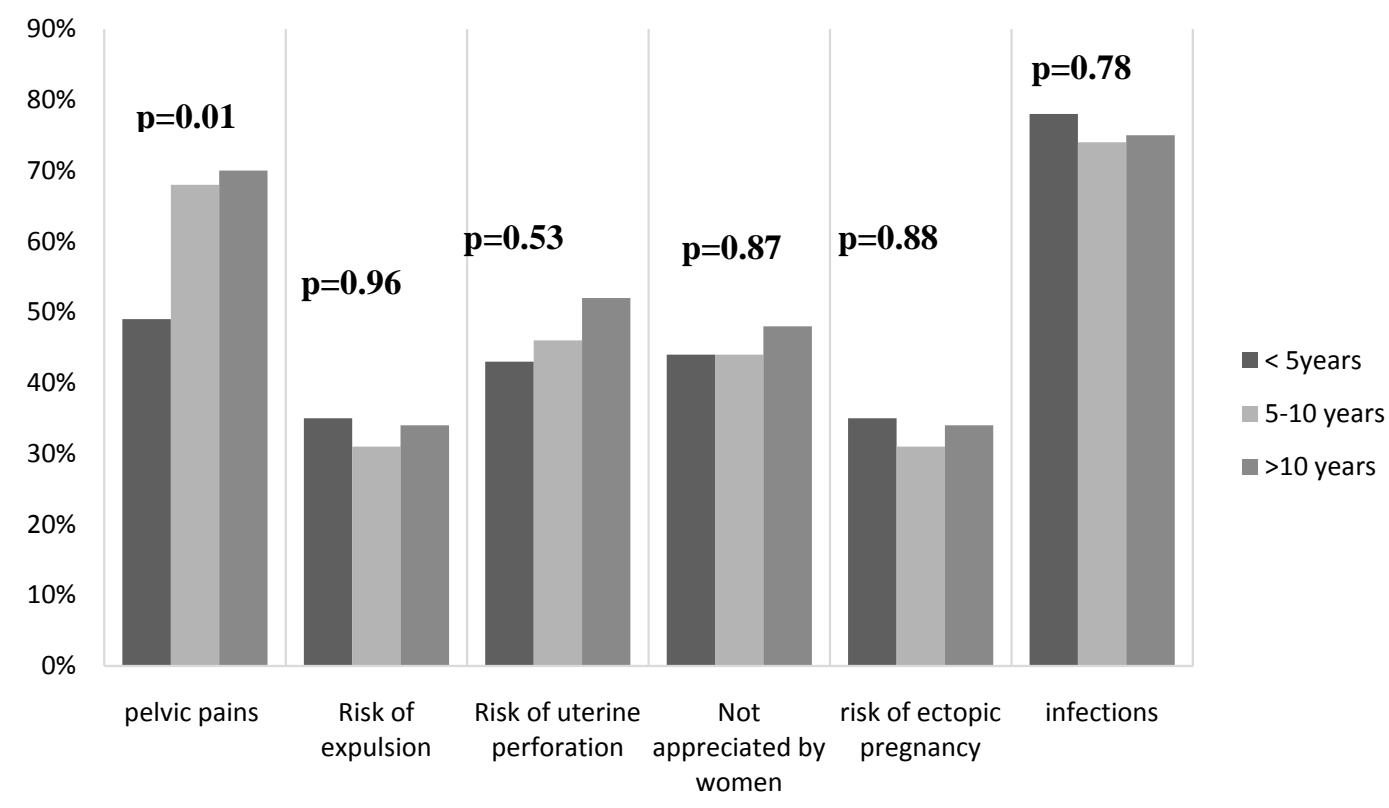

Figure 4. Perceived Obstacles to IUD Use by the years of experience.

\subsection{IUD and Parity}

In the multiple-choice question "for whom the IUD is indicated", $99.3 \%$ were for insertion in multiparous women, $67.4 \%$ in primiparous women, and only $40.5 \%$ in nulliparous women.

Multivariate analysis, comparing IUD indication by parity in age, occupation, gender, years of experience, and place of practice, found no statistically significant differences (Table 3 ). 
Table 3. Comparing the indication of the IUD by age, profession, gender, years of experience and place of practice.

\begin{tabular}{ccccc}
\hline & & Odds-Ratio & p & p global \\
\hline Profession & Gynecologist vs. midwives & $1.36[0.465 ; 4.26]$ & 0.58 & 0.62 \\
& intern/Specialist students vs. midwives & $0.748[0.256 ; 2.15]$ & 0.59 & - \\
\hline Age (years) & & $1.01[0.963 ; 1.07]$ & 0.64 & 0.64 \\
Years of experience & $<5$ years vs. 5 - 10 years & $1.43[0.653 ; 3.14]$ & 0.37 & 0.56 \\
\hline Place of practice & $>10$ years vs. 5 - 10 years & $1.28[0.634 ; 2.61]$ & 0.49 & - \\
\hline Sex & private and public vs. public & $1.85[0.666 ; 5.51]$ & 0.25 & 0.37 \\
\hline
\end{tabular}

The insertion of IUDs in primiparous and nulliparous women is a subject of contention. We found no statistically significant difference for nulliparous women by profession $(\mathrm{p}=0.57)$. However, for insertion in primiparous women, we found a significant difference, with gynecologists being more likely to prescribe it $(\mathrm{p}=0.03)($ Table 4$)$.

\subsection{Increasing IUD Prevalence}

When asked what would increase IUD use, the most common responses were awareness raising through advanced strategies and talks, providing the right information, managing rumors, emphasizing benefits, managing side effects, availability of IUDs throughout Senegal, and free IUDs. Also on the list was the training of providers on the theoretical and practical level in order to deepen their knowledge, provide better quality of care and disclose the right information to clients.

\section{Discussion}

All occupational categories agreed on the advantages of the IUD, which is a long-term, safe and reversible, highly effective method with a Pearl Index of about $0.1 \%$. It is also relatively inexpensive [1]. The IUD is still victim of misunderstanding and false rumors even among providers. Indeed, in this study, most of the barriers mentioned by professionals were infections, pelvic pain, expulsion, the risk of perforation and the risk of EP. Several studies have been conducted since the advent of the IUD and continue to be reassuring about these complications, which remain scarce.

Infections were most often reported by gynecologists compared to midwives and interns/Specialist students but without significant difference $(\mathrm{p}=0.87)$. There is evidence, however, that these infectious complications are more related to the sexual lifestyle of the user than to the IUD itself [7].

Pelvic pain is a common complaint among IUD users. These painful symptoms tend to subside over time and are easily relieved with nonsteroidal anti-inflammatory drugs or antispasmodic medications [3] [8] [9]. Midwives appear 
Table 4. IUD insertion in nulliparous and primiparous women by profession.

\begin{tabular}{|c|c|c|c|c|c|c|c|}
\hline & & $\begin{array}{l}\text { Profession Midwives } \\
\qquad(\mathrm{n}=222)\end{array}$ & $\begin{array}{l}\text { Profession Gynecologist } \\
\qquad(\mathrm{n}=37)\end{array}$ & $\begin{array}{l}\text { Profession intern/Des } \\
\qquad(\mathrm{n}=33)\end{array}$ & $\mathrm{n}$ & $\mathrm{p}$ & test \\
\hline \multirow{2}{*}{$\begin{array}{l}\text { IUD with the } \\
\text { nulliparous, } \mathrm{n}\end{array}$} & No & $193(87 \%)$ & $30(81 \%)$ & $29(88 \%)$ & 252 & 0.57 & Fisher \\
\hline & yes & $29(13 \%)$ & $7(19 \%)$ & $4(12 \%)$ & 40 & - & - \\
\hline \multirow{2}{*}{$\begin{array}{l}\text { IUD with the } \\
\text { primiparous, } \mathrm{n}\end{array}$} & yes & $110(50 \%)$ & $27(73 \%)$ & $17(52 \%)$ & 154 & 0.03 & Chi2 \\
\hline & No & $112(50 \%)$ & $10(27 \%)$ & $16(48 \%)$ & 138 & - & - \\
\hline
\end{tabular}

to be more sensitive to the occurrence of these pains, reporting them at $67 \%$ compared to $54 \%$ among gynecologists and $52 \%$ among interns/Specialist students. Compared to years of experience, those under 5 years of age appear to be less concerned about pelvic pain, reporting it at $49 \%$ versus $67 \%$ in 5 - 10 years of age and $70 \%$ in those over 10 years of age $(p=0.01)$.

Expulsions are scarce, occurring between $2 \%$ and $8 \%$ during the first year of use [10]. Perforation is a rare but potentially serious accident. Its incidence varies from 0.1 to 3 per 1000 exposures [1] [9] [10]. Inexperience or clumsiness of the operator is known to be a contributing factor [9]. Midwives and interns report more frequently the risk of expulsion and perforation than gynecologists ( $p$ $=0.96 ; \mathrm{p}=0.57)$. This is consistent with the hypothesis that a lack of experience and knowledge about IUD insertion technique limits its prescription for fear of possible complications, as gynecologists are usually better trained. In sum, these two complications alone should not constitute barriers in view of their low probability of occurrence.

There is currently evidence that IUD does not increase the risk of EP, and are even protective compared to women without contraception. The ectopic pregnancy rate would be $10 \%$ compared to women without contraception. The risk is estimated to be $0.02 \%$ to $0.25 \%$ for the IUD versus $0.5 \%$ for women without contraception [9]. Gynecologists were less likely to believe that the IUD would lead to an excess risk of EP, the explanation being a better understanding of side effects and complications.

Although the majority of participants, $71 \%$, made more than 10 to 20 contraceptive visits per month, the IUD prescription and insertion rate were low at less than 5 per month in $75 \%$ of cases. Indeed, the IUD is often combined with permanent contraception for elderly, large multiparous patients who no longer wish to become pregnant. Multivariate analysis, comparing IUD indication according to parity in age, profession, sex, years of experience and place of practice, did not find any statistically significant difference.

IUD indication in nulliparous women is not a common practice in our regions, due to several factors: religious beliefs, false rumors, lack of knowledge of the mechanism of action, fear of secondary infertility and many others. Moreover, this indication constitutes a problem shared throughout the world [7] [8] [11]. In the Swiss study, only a minority of participants (11.8\%) frequently in- 
serted the IUD in nulliparous women [12]. In our study, 19\% of the gynecologists said they were used to inserting the IUD in nulliparous women, compared with $13 \%$ of the midwives and $12 \%$ of the interns and Specialist students $(\mathrm{p}=$ 0.57). The safety of the IUD in nulliparous women is supported by international recommendations for medical eligibility criteria [8], but some practitioners remain cautious about prescribing it in this population.

The parity barrier seems to be more of a concern for midwives and students. Indeed, $73 \%$ of gynecologists do insertions in primiparous women compared to $50 \%$ for midwives and $52 \%$ for interns, with a statistically significant difference $\mathrm{p}$ $=0.03$ This means that slightly more than half of patients will not be offered the IUD because of their primiparity by some practitioners, namely midwives and students. The explanation would be that these providers reserve the IUD for older women and large multiparous women, perhaps forgetting that it is a reversible contraceptive method with immediate return to fertility upon withdrawal. Gynecologists may be more experienced and have better grasp of the indications.

Another obstacle mentioned was women's lack of appreciation of the IUD. It is reported by $46 \%$ of midwives, $43 \%$ of gynecologists and $36 \%$ of interns and Specialist students $(\mathrm{p}=0.51)$. The knowledge of the IUD and its understanding by the users is an imperative to increase its prevalence [4] [13]. Indeed, many women refer to the IUD as a barbaric, dangerous, painful contraceptive that causes pain, heavy bleeding and infection [13] [14].

These concerns, combined perhaps with a lack of knowledge and/or skills among providers, reinforce obstacles [4] [6].

\section{Conclusions}

Our study reveals that providers' apprehensions and concerns severely limit the availability of IUD.

These concerns are usually unfounded, based on personal experiences and not on official recommendations. Parity is a major obstacle, especially for midwives. This may be due to a lack of knowledge. Additional training and a review of national and international guidelines could greatly reassure providers and reduce attitudinal differences in IUD prescribing.

\section{Ethical Considerations}

Participation in this study was voluntary and concerned health professionals. The questionnaires were anonymized and confidentiality was respected.

\section{Conflicts of Interest}

The authors declare no conflicts of interest regarding the publication of this paper.

\section{References}

[1] Diallo, M., Daff, H.M.B., et al. (2019) Intrauterine Device in the Immediate Post- 
partum: Study Comparing insertion after Cesarean and Vaginal Delivery. Open Journal of Obstetrics and Gynecology, 9, 1510-1518.

[2] Gueye, M., Gaye, Y.F.O., et al. (2013) Intrauterine Device Inserted during Cesarean Section. Pilot Study Conducted at the Dakar University Hospital Journal of Obstetrics and Reproductive Biology, 42, 585-590.

https://doi.org/10.1016/j.jgyn.2013.06.003

[3] Lopez, L.M., Bernholc, A., Hubacher, D., Stuart, G. and Van Vliet, H.A.A.M. (2015) Immediate Postpartum Insertion of Intrauterine Device for Contraception. Cochrane Database of Systematic Reviews, No. 6, Art. No.: CD003036. https://doi.org/10.1002/14651858.CD003036.pub3

[4] Nguer, R. and Reynolds, H.W. (2004) Evaluation of the Decline in IUD Use in Senegal. USAID, 55.

[5] ANSD (2017) Senegal: Continuing Demographic and Health Survey (EDS-Continue) ANSD and ICF, 2016.

[6] Aziz, M., Ahmed, S. and Ahmed, B. (2017) Attitudes of Physicians Providing Family Planning Services in Egypt about Recommending Intrauterine Device for Family Planning Clients. Sexual \& Reproductive Healthcare, 14, 64-68. https://doi.org/10.1016/j.srhc.2017.09.004

[7] Black, K.I., et al. (2013) Global Survey of Healthcare Practitioners' Beliefs and Practices around Intrauterine Contraceptive Method Use in Nulliparous Women. Contraception, 88, 650-656. https://doi.org/10.1016/j.contraception.2013.06.005

[8] Aoun, J., et al. (2014) Effects of Age, Parity, and Device Type on Complications and Discontinuation of Intrauterine Devices. Obstetrics \& Gynecology, 123, 585-592. https://doi.org/10.1097/AOG.0000000000000144

[9] Gronier, H. (2012) 15 Questions and Answers on Intrauterine Contraception. Gynécologie Obstétrique \& Fertilité, 40, 37-42.

https://doi.org/10.1016/j.gyobfe.2011.07.022

[10] Rowlands, S., Oloto, E. and Horwell, D.H. (2016) Intrauterine Devices and Risk of Uterine Perforation: Current Perspectives. Open Access Journal of Contraception, 7, 19-32. https://doi.org/10.2147/OAJC.S85546

[11] Luchowski, A.T., et al. (2014) Obstetrician-Gynecologists and Contraception: Practice and Opinions about the Use of IUDs in Nulliparous Women, Adolescents and Other Patient Populations. Contraception, 89, 572-577. https://doi.org/10.1016/j.contraception.2014.02.008

[12] Zimmermann, Y., Viviano, M. and Yaron, M. (2019) Swiss Gynecologists' Opinions and Perceptions Concerning the Use of Intrauterine Devices by Nulliparous and Multiparous Women: An Online Survey Study. International Journal of Women's Health, 11, 153-159. https://doi.org/10.2147/IJWH.S189051

[13] Gutin, S.A., et al. (2011) Survey of Knowledge, Attitudes and Practices Surrounding the Intrauterine Device in South Africa. Contraception, 83, 145-150.

https://doi.org/10.1016/j.contraception.2010.07.009

[14] Mathurin, K., Volumenie, J.-L., Flechelles, O., Derancourt, C. and Bonnier, C. (2018) Use and Representations of Intrauterine Device in Martinique, F.W.I.: A Cross-Sectional Survey. Journal of Gynecology Obstetrics and Human Reproduction, 47, 241-245. https://doi.org/10.1016/j.jogoh.2018.02.006 